\title{
Pulmonary vascular dilatation and diffusion-dependent impairment of gas exchange in liver cirrhosis
}

\author{
A.B.H. Crawford, J. Regnis, L. Laks, P. Donnelly, L.A. Engel, I.H. Young
}

Pulmonary vascular dilatation and diffusion-dependent impairment of gas exchange in liver cirrhosis. A.B.H. Crawford, J. Regnis, L. Laks, P. Donnelly, L.A. Engel, I.H. Young. CERS Journals Ltd 1995.

ABSTRACT: To test the hypothesis that diffusion-limitation for oxygen is due to abnormal vascular dilatation and significantly contributes to the arterial hypoxaemia of liver cirrhosis requires an experimental approach that detects both diffusion-limitation for oxygen and the presence of abnormal dilatation of pulmonary vessels exposed to alveolar gas.

We therefore studied the gas exchange of a 64 year old man with alcoholic liver cirrhosis and severe resting arterial hypoxaemia (arterial oxygen tension $\left(P_{\mathrm{a}}, \mathrm{O}_{2}\right)$ $7.5 \mathrm{kPa}$ ) whilst breathing air and $100 \% \mathrm{O}_{2}$ using conventional blood gas (CBG) analysis, the multiple inert gas elimination technique (MIGET) and whole body scintigraphy (WBS) following the i.v. administration of radiolabelled boli of macroaggregates with a minimum diameter of $15 \mu \mathrm{M}$.

During air breathing, there was a consistently positive difference between the arterial oxygen tension predicted by MIGET and that actually measured (P-M $P \mathrm{a}, \mathrm{O}_{2}$, average $0.9 \mathrm{kPa}$ ). During $\mathrm{O}_{2}$ breathing, $\mathrm{P}-\mathrm{M} \mathrm{Pa}, \mathrm{O}_{2}$ became negative, (average $-12.2 \mathrm{kPa})$, and shunt estimated by the $\mathrm{O}_{2}$ method $\left(\%\right.$ of $\left.Q^{\prime}\right)$ was consistently less than that measured by MIGET. Whereas both $\mathrm{O}_{2}$ method and MIGET estimates of shunt never exceeded $25 \%$, the WBS shunt was $40 \%$, indicating that a substantial fraction of cardiac output flowed through abnormally dilated pulmonary vessels, some of which were exposed to alveolar gas and, hence, participated in gas exchange.

Although our observations pertain to one subject, we believe they provide the most convincing in vivo evidence to date that abnormal dilatation of interalveolar vessels may, per se, result in a significant diffusion impairment for $\mathrm{O}_{2}$. Furthermore, in view of the consistently negative $\mathrm{P}-\mathrm{M} \mathrm{Pa}, \mathrm{O}_{2}$ observed during oxygen breathing, we speculate that such abnormal vascular dilatation may also have produced a significant diffusive impairment of one or more of the less soluble inert gases used in the MIGET analysis.

Eur Respir J., 1995, 8, 2015-2021.
Depts of Respiratory Medicine, Westmead Hospital, and Royal Prince Alfred Hospital, Sydney, Australia.

Correspondence: A.B.H. Crawford

Dept of Respiratory Medicine

Westmead Hospital

Westmead NSW 2145

Australia

Keywords:

mutiple inert gas elimination technique oxygen

radionuclide macroaggregate technique shunt sulphur hexafluoride

venous admixture

Received: December 161993

Accepted after revision June 161995

This work was supported by the National Health and Medical Research Council of Australia and the Institute of Respiratory Medicine, Royal Prince Alfred Hospital.
Patients with significant arterial hypoxaemia and liver cirrhosis are known to have extensive pulmonary vascular dilatation, which is largely interalveolar in location [1-3]. It has been postulated that blood flowing through such dilated interalveolar vessels may not fully equilibrate with alveolar gas because of the increased distance between the alveolar-capillary membrane and red blood cells, resulting in a diffusive impairment to oxygen uptake $[4,5]$. This mechanism has been proposed to explain why, when such patients breathe $100 \%$ oxygen, there is typically both a marked increase in arterial oxygen tension $\left(\mathrm{Pa}, \mathrm{O}_{2}\right)$ and a substantial negative discrepancy between functional and "anatomical" shunt fractions as quantified by the conventional oxygen method and radionuclide macroaggregate technique, respectively [4-8]. These observations, whilst collectively indicative of abnormal interalveolar vascular dilatation, are not sufficiently specific to validate the actual presence of diffusion-limitation for oxygen. Thus, significant inequality of alveolar ventilationperfusion ratios $\left(V^{\prime} \mathrm{A} / Q^{\prime}\right)$ could equally explain a marked improvement in arterial $\mathrm{Pa}, \mathrm{O}_{2}$ with $100 \%$ oxygen breathing. Indeed, recent studies using the multiple inert gas elimination technique (MIGET), an analysis which can indirectly detect oxygen diffusion-limitation, have attributed the arterial hypoxaemia in patients with liver cirrhosis to $V^{\prime} \mathrm{A} / Q^{\prime}$ inequality and intrapulmonary shunting [9-11]. However, none of these MIGET studies has providedany direct evidence of actual pulmonary vascular dilatation; and, hence, they do not, by themselves, invalidate the specific hypothesis that diffusionlimitation for oxygen can occur as a direct consequence of abnormal dilatation of interalveolar vessels.

To adequately test the above hypothesis requires an experimental approach that has the power to simultaneously 
detect both diffusion-limitation for oxygen and the presence of abnormal dilatation of pulmonary vessels exposed to alveolar gas. Since the MIGET analysis and radionuclide macroaggregate technique, respectively, fulfil these criteria, we utilized both methods to assess the pulmonary gas exchange of a 64 year old man with alcoholic liver disease and severe arterial hypoxaemia, whilst breathing air and $100 \%$ oxygen.

\section{Subject and methods}

A 64 year old retired forestry worker presented with a 5 year history of progressive exertional dyspnoea. He admitted to an alcohol consumption of $60 \mathrm{gm} \cdot \mathrm{day}^{-1}$ for $30 \mathrm{yrs}$, and a 30 pack-year smoking history. Examination revealed a moderately obese man with gross finger clubbing and extensive spider naevi, who became cyanosed on mild exertion. Examination of his respiratory and cardiovascular systems was normal. His liver was enlarged, with a span of $16 \mathrm{~cm}$, but there was no clinical evidence of splenomegaly or abdominal ascites. Chest radiographic image appeared completely normal. Liver scan revealed an enlarged liver with generalized poor and patchy uptake. Routine liver function tests revealed a mildly reduced serum albumin of $33 \mathrm{~g} \cdot \mathrm{L}^{-1}$ (normal 35-45 g. $\left.\mathrm{L}^{-1}\right)$ and mildly increased total bilirubin of $26 \mu \mathrm{mol} \cdot \mathrm{L}^{-1}$ (normal $\left.2-21 \mu \mathrm{mol} \cdot \mathrm{L}^{-1}\right)$. Antipyrine clearance was markedly impaired $\left(0.17 \mathrm{~mL} \cdot \mathrm{min}^{-1} \cdot \mathrm{kg}\right.$, normal range $0.34-1.02 \mathrm{~mL} \cdot \mathrm{min}^{-1} \cdot \mathrm{kg}$ ), and liver biopsy showed a histological picture consistent with inactive alcoholic cirrhosis. Pulmonary function tests revealed mild airflow obstruction with a forced expiratory volume in one second (FEV1) and forced vital capacity (FVC) of 70 and 79\% predicted, respectively, and an FEV1/FVC ratio of 69\%. Lung volumes measured by body plethysmography were also slightly reduced with total lung capacity (TLC) and vital capacity (VC) both 78\% pred. Transfer factor for carbon monoxide, measured by the singlebreath helium method, was markedly impaired (34\% pred). Arterial blood gas determination breathing room air showed $\mathrm{Pa}, \mathrm{O}_{2} 7.3 \mathrm{kPa}$, arterial carbon dioxide tension $\left(P \mathrm{a}, \mathrm{CO}_{2}\right) 3.1 \mathrm{kPa}$ and $\mathrm{pH} 7.45$. A contrast bubble echocardiogram using a transoesophageal lead showed normal biventricular size and function with no evidence of an intracardiac shunt. However, delayed echogenecity was observed in the left heart chambers approximately three cardiac cycles after its detection in the right heart chambers, consistent with the presence of intrapulmonary shunt [7].

The patient was then studied on three consecutive days. On days 1 and 3, $135 \mathrm{MBq}$ of ${ }^{99 \mathrm{~m}} \mathrm{Tc}$-labelled albumen macroaggregates (mean size $=20 \mu \mathrm{m}$, range $15-50 \mu \mathrm{m}$ ) were injected into an antecubital vein, while the patient was sitting erect breathing air and while breathing 100\% $\mathrm{O}_{2}$ for $30 \mathrm{~min}$, respectively. After $5 \mathrm{~min}$, the subject then adopted the supine posture and whole body scintigraphy was performed over the subsequent 15 min using a large field of view gamma camera linked to a dedicated micro-delta nuclear medicine computer (Siemens). Counts were collected from anterior and posterior images of the lungs, abdomen and legs, as well as right and left lateral images of the head and anterior images of the arms. For each image, counts were collected for $1 \mathrm{~min}$, and where two views were involved, these counts were averaged. Counts emanating from the thyroid gland were excluded from the analysis. The percentage of radiolabelled macroaggregates shunted from pulmonary to systemic circulation was calculated by the equation proposed by GATES et al. [12]:

$$
\frac{\text { total body counts-total lung counts }}{\text { total body counts }} \times 100=\begin{aligned}
& \% \text { right-to- } \\
& \text { left shunt }
\end{aligned}
$$

This is a quantitative measure of the percentage of cardiac output flowing through vessels $>15 \mu \mathrm{m}$ in diameter. This method has been documented to give estimates of shunt that closely correspond with those measured by the classical $\mathrm{O}_{2}$ method, both in pulmonary disease with known large arterio-venous (A-V) malformations [13] and in intracardiac right-left (R-L) shunts [12]. Using the same batch of macroaggregates, whole body scintiscans were performed on two patients with suspected pulmonary emboli on days 1 and 3, and the calculated shunt estimates were 3 and $4 \%$, respectively. On both study days, radiopharmaceutical analysis found $>97 \%$ of ${ }^{99 \mathrm{~m}} \mathrm{Tc}$ was bound to the albumen macroaggregates.

On day 2, gas exchange was studied using conventional blood gas analysis and the MIGET. The latter analysis has been described in detail by WAGNER and co-workers [14], and our application of it has been published [15]. Six inert gases (acetone, diethyl ether, enflurane, cyclopropane, ethane and sulphur hexafluoride $\left(\mathrm{SF}_{6}\right)$ dissolved in normal saline) were infused intravenously, and mixed venous and arterial blood was sampled from indwelling pulmonary and radial arterial catheters. The subject wore a noseclip and breathed through a mouthpiece. Blood and expired gas were sampled whilst the subject, in the seated posture, breathed air (three runs), and $100 \% \mathrm{O}_{2}$ for $30 \mathrm{~min}$ ( 2 runs). One run was also obtained in the supine posture whilst breathing $100 \% \mathrm{O}_{2}$. Cardiac output was measured from the mass balance characteristics of the inert gases. Haemoglobin and haematocrit were measured, as was the partial pressure of $\mathrm{O}_{2}$ required to achieve 50\% saturation of arterial blood (P50). Oxygen tension $\left(\mathrm{PO}_{2}\right)$ and carbon dioxide tension $\left(\mathrm{PCO}_{2}\right)$ were measured from both arterial and mixedvenous samples using a Corning 178 automatic $\mathrm{pH} / \mathrm{blood}$ gas system. This system was automatically calibrated throughout the study period with serial one and two point calibrations every 15 and $60 \mathrm{~min}$, respectively $\left(\mathrm{PO}_{2}\right.$ range $\left.0-11.5 \mathrm{kPa}\right)$. Under these operating conditions, the Corning 178 has been documented to show only a small degree of imprecision, even at relatively high $\mathrm{PO}_{2}(95 \%$ confidence limits $= \pm 2.4 \mathrm{kPa}$ at a $\mathrm{Pa}, \mathrm{O}_{2}$ of $50.3 \mathrm{kPa}$; manufacturer's instructions, Corning 178). As a further check, we subsequently tested the individual accuracies of both gas electrodes, previously calibrated as above, with blood equilibrated for $40 \mathrm{~min}$ with a gas mixture containing $40.3 \% \mathrm{O}_{2}$ and $6.0 \% \mathrm{CO}_{2}$, the concentrations of which were validated by standard electro-chemical and Haldane techniques, respectively. Predicted $\mathrm{PO}_{2}$ for the equilibrated blood was $38.5 \mathrm{kPa}$. 
Table 1. - Haemodynamic and respiratory gas exchange results

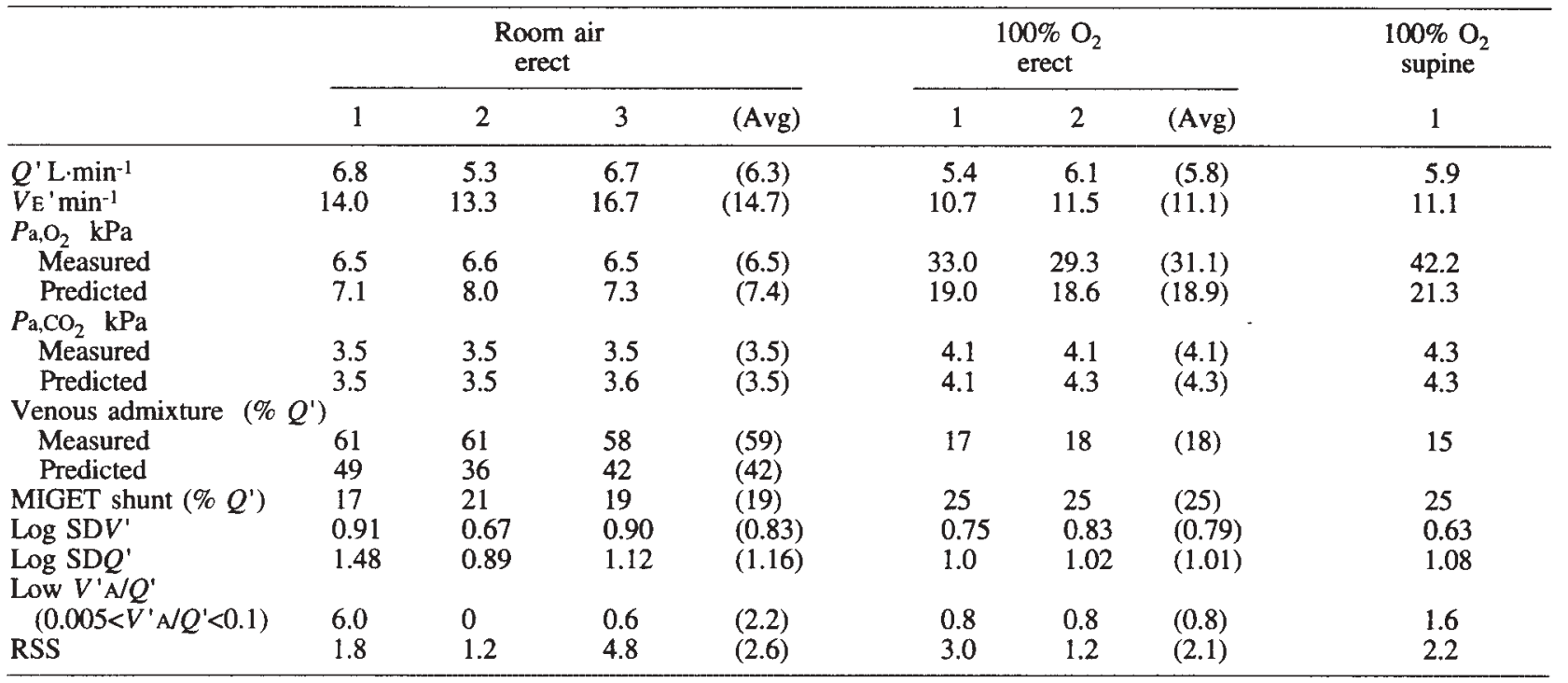

Haemoglobin (Hb): $175 \mathrm{~g} \cdot \mathrm{L}^{-1}$; haematoerit (Het): 0.50; P50: $5.0 \mathrm{kPa} . Q^{\prime}$ : cardiac output; $V^{\prime} \mathrm{E}$ : minute ventilation; $P$ a, $\mathrm{O}_{2}:$ arterial oxygen tension; $\mathrm{Pa}, \mathrm{CO}_{2}$ : arterial carbon dioxide tension; MIGET: multiple inert gas elimination technique; $\log \mathrm{SD} Q^{\prime}, \log \mathrm{SD} V^{\prime}$ : dipersions of blood flow and ventilation distribution, respectively; Low $V^{\prime} \mathrm{A} / \mathrm{Q}^{\prime}$ : perfusion of poorly ventilated (relative perfusion) lung unites $(0.005<$ $\left.V^{\prime} \mathrm{A} / \mathrm{Q}^{\prime}<0.1\right)$ in \% of cardiac output; RSS: residual sum of squares; P50: the partial pressure of $\mathrm{O}_{2}$ required to achieve $50 \%$ saturation of arterial blood: Avg: average.

This compared with duplicate $\mathrm{PO}_{2}$ measurements obtained from each electrode of $38.1,38.3 \mathrm{kPa}$ and 38.0 , $38.8 \mathrm{kPa}$, respectively. Mixed venous and arterial contents for both gases were derived. Venous admixture $\left(\% Q^{\prime}\right)$ was calculated both during air and $100 \% \mathrm{O}_{2}$ breathing by the standard equation

$$
Q^{\prime} \mathrm{s} / Q^{\prime} \mathrm{t}=\mathrm{Ci}, \mathrm{O}_{2}-\mathrm{Ca}, \mathrm{O}_{2} / \mathrm{Ci}, \mathrm{O}_{2}-\mathrm{C} \overline{\mathrm{v}}, \mathrm{O}_{2}
$$

where $\mathrm{Ci}, \mathrm{Ca}$ and $\mathrm{C} \overline{\mathrm{V}}$ equal the oxygen content of ideal, arterial and mixed-venous blood, respectively. The partial pressures of the inert gases were measured for the arterial, mixed venous and expired gas samples, their retentions and excretions were derived, and the distribution of ventilation-perfusion as a function of ventilationperfusionratio $\left(V^{\prime} \mathrm{A} / Q^{\prime}\right)$ were determined. From MIGET we obtained the inert gas shunt and predicted $P \mathrm{a}, \mathrm{O}_{2}$ on air and oxygen, and the predicted venous admixture on air.

\section{Results}

During air breathing, the predicted $\mathrm{Pa}_{\mathrm{a}} \mathrm{O}_{2}$ was consistently greater than measured $\mathrm{Pa}, \mathrm{O}_{2}\left(\mathrm{P}-\mathrm{M} P \mathrm{a}, \mathrm{O}_{2}\right)$ with an average difference of $0.9 \mathrm{kPa}$ (table 1). Despite a moderate degree of $V^{\prime} \mathrm{A} / Q^{\prime}$ inequality, as quantified by the indices $\log \mathrm{SD} Q^{\prime}$ and $\log \mathrm{SD} V$, only a negligible quantity of $Q^{\prime}$ perfused low $V^{\prime} \mathrm{A} / Q^{\prime}<0.1$ (table 1 ). Partitioning of the total venous admixture predicted by MIGET into that due to $V^{\prime} \mathrm{A} / Q^{\prime}$ inequality and pure shunt revealed equivalent contributions from each mechanism. However, consistent with the positive P-M $\mathrm{Pa}, \mathrm{O}_{2}$, the predicted venous admixture was substantially less than that actually measured (42\% vs $59 \%$ of $Q^{\prime}$, respectively; (table 1 and fig 1). During $\mathrm{O}_{2}$ breathing, there was little change in the measured degree of $V^{\prime} \mathrm{A} / Q^{\prime}$ inequality. However, the P-M $P \mathrm{a}, \mathrm{O}_{2}$ was negative in both runs

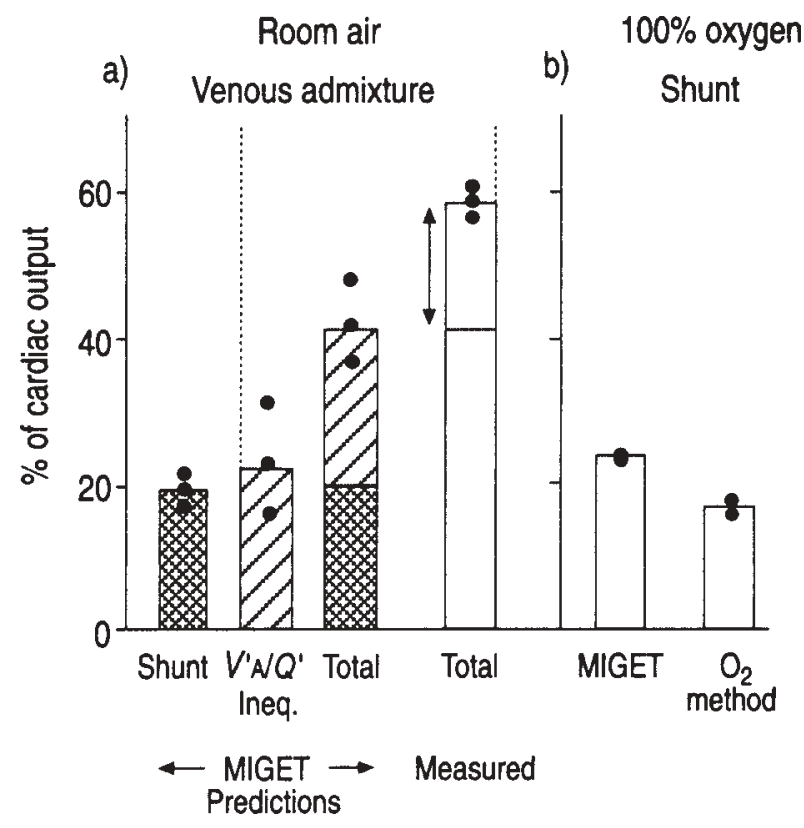

Fig. 1. - a) Comparison of the MIGET predictions for venous admixture and that measured from conventional blood gas analysis during air breathing. Note that the total predicted venous admixture is composed of pure shunt and that venous admixture resulting from the MIGET-derived estimate of $V^{\prime} \mathrm{A} / Q^{\prime}$ inequality. The difference between the mean measured and predicted venous admixture (double-headed arrow) quantifies the magnitude of the gas impairment due to diffusion-limitation. b) Comparison of the MIGET estimate shunt with that obtained from conventional blood gas analysis during oxygen breathing in the erect posture $\left(\mathrm{O}_{2}\right.$ method). Note that the MIGET shunt values are consistently greater than those estimated by the $\mathrm{O}_{2}$ method. MIGET: multiple inert gas elimination technique; $V^{\top} \mathrm{A} / Q^{\prime}$ : alveolar ventilation/perfusion. 
(average $=-12.2 \mathrm{kPa}$ ), and the MIGET estimate of shunt was greater than that measured by the $\mathrm{O}_{2}$ method $(25 \mathrm{vs}$ $18 \%$ of $Q^{\prime}$, respectively). Similar discrepancies were also apparent in the single run performed in the supine posture (table 1). During air and $100 \% \mathrm{O}_{2}$ breathing, the radiolabelled macroaggregate estimates of shunt were 41 and $40 \%$ of $Q^{\prime}$, respectively, considerably exceeding that measured by MIGET on air and by MIGET and $\mathrm{O}_{2}$ methods on $100 \% \mathrm{O}_{2}$ (table 1 ).

\section{Discussion}

Both in vivo angiography and postmortem studies of patients with liver disease and arterial hypoxaemia have consistently documented the presence of extensive pulmonary vascular dilatation, which is limited mainly to those vessels exposed to alveolar gas [1-3, 7]. As observed in our current subject, these patients typically show a substantial increase in $\mathrm{Pa}, \mathrm{O}_{2}$ on breathing $100 \%$ oxygen, and measurements of intrapulmonary "anatomical" shunt using the radionuclide macroaggregate technique substantially exceed functional estimates of shunt as measured by the $\mathrm{O}_{2}$ method $[2,7,8]$. Taken together, these observations have been interpreted as convincing evidence that diffusion-limitation of $\mathrm{O}_{2}$ due to alveolar vascular dilatation is a significant contributory mechanism to the arterial hypoxaemia associated with liver disease $[2,5,7]$.

On the other hand, AGUSTI et al. [11] have argued that only studies utilising the MIGET analysis can satisfactorily examine the potential role of diffusion-limitation in the overall pulmonary gas exchange of such patients, and have concluded that, even in the presence of moderate arterial hypoxaemia, the role of diffusion-limitation appears negligible. However, only two studies, each involving six subjects, have specifically used the MIGET analysis to assess gas exchange in patients with liver disease and moderate to severe arterial hypoxaemia $\left(\mathrm{Pa}_{\mathrm{a}} \mathrm{O}_{2}\right.$ $<9.3 \mathrm{kPa})[10,16]$. In both patient groups, as in our subject, there were significant differences between $\mathrm{Pa}, \mathrm{O}_{2}$ predicted by MIGET and $P \mathrm{a}, \mathrm{O}_{2}$ actually measured (P-M $\mathrm{Pa}_{\mathrm{a}} \mathrm{O}_{2}, 0.7$ and $1.3 \mathrm{kPa}$, respectively). The authors of both studies proposed postpulmonary shunting as the most likely explanation for the observed P-M $P \mathrm{a}, \mathrm{O}_{2}$ differences. However, such a mechanism would not explain the complete abolition of the P-M $P \mathrm{a}, \mathrm{O}_{2}$ when breathing $100 \% \mathrm{O}_{2}$, as observed by EDELL et al. [10] and in our current subject. Moreover, physiological postpulmonary shunting would appear insufficient to account for the observed P-M $P$ a, $\mathrm{O}_{2}$ differences, particularly at $P \mathrm{a}, \mathrm{O}_{2}<8.0$ $\mathrm{kPa}$. Similarly, portopulmonary anastomosis have only rarely been identified [1] and, when present, carry only small quantities of blood which is relatively $\mathrm{O}_{2}$ rich [17]. $\mathrm{We}$, therefore, believe that the consistent $\mathrm{P}-\mathrm{M} \mathrm{Pa}, \mathrm{O}_{2}$ differences obscrved in our subject and those of EDELL et al. [10] and CASTAING and MANIER [16] are most likely to represent a significant diffusion impairment for $\mathrm{O}_{2}$ occurring at the alveolo-capillary level. In our subject, such diffusion-limitation contributed equally with right-left shunting and $V^{\top} \mathrm{A} / Q^{\prime}$ inequality to the overall impairment of $\mathrm{O}_{2}$ gas exchange when quantified in terms of venous admixture (fig. 1). Whereas the MIGET analysis can indirectly detect the presence of diffusion-limitation and quantify its relative contribution to arterial hypoxaemia, it cannot, alone, identify the presence of abnormal vascular dilatation. Similarly, the radionuclide macroaggregate (RM) estimate of intrapulmonary shunt, whilst providing anatomical evidence of abnormal pulmonary vascular dilatation, cannot quantify the contribution that such an abnormality may functionally have on overall gas exchange. In our subject, both MIGET and $\mathrm{O}_{2}$ estimates of shunt are considerably less than that estimated by the RM method (table 1), indicating that a substantial fraction of the injected radionuclide macroaggregates must have passed from the pulmonary to systemic circulations via dilated vascular channels which are exposed to alveolar gas and participate in gas exchange. Otherwise, there should have been no observed differences between functional estimates of shunt (i.e. MIGET and $\mathrm{O}_{2}$ methods) and that measured by the RM method. It therefore seems reasonable to conclude that the observed diffusion-limitation for $\mathrm{O}_{2}$ is most likely to be a consequence of the demonstrated alveolar vascular dilatation.

Theoretical and in vitro studies provide substantial evidence for significant diffusion-limitation to $\mathrm{O}_{2}$ uptake in blood flowing in vessels larger than $20 \mu \mathrm{m}$. The flow profile in such vessels is parabolic and, because of sheer forces, red blood cells (RBC) tend to move away from the vessel wall resulting in a radial distribution of haematocrit [18]. Thus, for blood flowing in the centre, as opposed to that flowing along the wall, not only is there a greater overall alveolo-capillary distance for $\mathrm{O}_{2}$ molecules to diffuse, but its transit time is effectively shortened and it contains a greater concentration of potential $\mathrm{O}_{2}$ carrying $\mathrm{RBC}$. Furthermore, the diffusivity of oxygen within this increased "alveolar-capillary distance" is likely to be substantially reduced by intervening high resistance plasma layers $[19,20]$.

An intriguing observation of the current study is that in all three oxygen runs the measured $\mathrm{Pa}, \mathrm{O}_{2}$ values were consistently greater than those predicted by the MIGET analysis (table 1). Similarly, in two of the three patients with liver disease and arterial hypoxaemia recently reported by EDELL et al. [10], the measured $\mathrm{Pa}_{\mathrm{a}} \mathrm{O}_{2}$ values were greater than those predicted by MIGET during $\mathrm{O}_{2}$ breathing. These findings contrast with previously published studies using the MIGET analysis in both normal and patient groups breathing $100 \% \mathrm{O}_{2}$, in whom the measured $\mathrm{Pa}, \mathrm{O}_{2}$ values were invariably substantially less than those predicted by MIGET [14, 21, 22]. In our own laboratory, using essentially the same experimental protocol and technical equipment as in the current study, we have never previously observed the measured $\mathrm{Pa}, \mathrm{O}_{2}$ to exceed that predicted by MIGET in a large number of both normal subjects and patients with varying lung disorders when breathing $100 \% \mathrm{O}_{2}$ [23]. Indeed, inevitable leaks in the $\mathrm{O}_{2}$ delivery system, deterioration of the arterial blood samples prior to analysis, and insensitivity of the MIGET analysis to detect physiological postpulmonary shunt should all conspire to produce a positive $\mathrm{P}-\mathrm{M} \mathrm{Pa}, \mathrm{O}_{2}$ during $100 \% \mathrm{O}_{2}$ breathing $[14,21]$. Particularly in view of our 
limited data base, experimental error could explain our observation, the most likely sources being in the actual measurement of $P \mathrm{a}, \mathrm{O}_{2}$ and/or in the MIGET analysis. It would seem unlikely that there were significant errors in our $\mathrm{Pa}, \mathrm{O}_{2}$ measurements (see Methods). The greater shunt estimate as measured by MIGET compared with the $\mathrm{O}_{2}$ method, raises the possibility that the former may have been overestimated either as a consequence of MIGET's known inability to separate pure shunt $\left(V^{\prime} \mathrm{A} / Q^{\prime}=0\right)$ from very low $V^{\prime} \mathrm{A} / Q^{\prime}$ units $\left(V^{\prime} \mathrm{A} / Q^{\prime}<0.005>0\right)$, or because of fitting error in the recovered distributions. Neither of these possibilities appear likely since for the three oxygen runs the maximum observed $\%$ of $Q^{\prime}$ going to $V^{\prime} \mathrm{A} / Q^{\prime}$ units $<0.1$ was $1.6 \%$, and the goodness of fit of the recovered distributions, as quantified by the residual sum of squares, was excellent for all runs and comparable during air and $\mathrm{O}_{2}$ breathing (table 1).

An alternative explanation is that the inert gas $\mathrm{SF}_{6}$, the second heaviest of the six inert gases and the gas exchange characteristics of which are the principal determinant of the MIGET shunt, was also partially diffusion-limited. Such diffusion-limitation would presumably still be less than that for $\mathrm{O}_{2}$ during air breathing, hence still permitting our observation of a positive $\mathrm{P}-\mathrm{M} \mathrm{Pa}, \mathrm{O}_{2}$. However, during $100 \% \mathrm{O}_{2}$ breathing, the corresponding sixfold increase in the alveolo-capillary $\mathrm{O}_{2}$ gradient may have been sufficient to specifically reduce the diffusion-limitation for $\mathrm{O}_{2}$, such that it actually became less than that for $\mathrm{SF}_{6}$. This would be consistent with the observed greater MIGET estimate of shunt compared with that estimated by the $\mathrm{O}_{2}$ method and the corresponding negative P-M $\mathrm{Pa}_{\mathrm{a}} \mathrm{O}_{2}$ (table 1). Breathing $100 \% \mathrm{O}_{2}$, by releasing hypoxic vasoconstiction, may also have resulted in a further increase in the diameter of those intra-alveolar vessels already abnormally dilated, thus further predisposing $\mathrm{SF}_{6}$ to diffusion-limitation. This would neatly explain the increase in MIGET shunt observed during $\mathrm{O}_{2}$ breathing (table 1). The alternative explanation of oxygen-induced atelectasis would appear distinctly unlikely, as there was neither evidence of any units with very low $V^{\prime} \mathrm{A} / Q^{\prime}$ ratios during air breathing nor any apparent loss of units with low $V^{\prime} \mathrm{A} / Q^{\prime}$ ratios during $\mathrm{O}_{2}$ breathing.

The commonly held belief that inert gases are not diffusion-limited is based on a theoretical analysis of alveolocapillary gas equilibration, which predicts that even the heaviest of the inert gases should equilibrate an order of magnitude more quickly than the physiological gases $\mathrm{O}_{2}$ and $\mathrm{CO}_{2}$ [24]. However, this analysis assumes instantaneous radial diffusive equilibration of the inert gases at all times within the body of blood as it passes through the alveolar capillary. Whereas such an assumption may be reasonable in a normal sized capillary, in the dilated alveolar vessel diffusing distances will be correspondingly increased. From the Fick equation, the effective intravascular diffusivity of a given inert gas (and hence its likelihood of achieving intravascular equilibration) will be directly proportional to its solubility in blood $(\lambda)$ and inversely proportional to the square root of its molecular weight $(\sqrt{ } \mathrm{MW})$. Since for the MIGET gases the range of $\lambda(0.00578-220.65)$ is much greater than $\sqrt{ } \mathrm{MW}$ (5.20-13.82), $\lambda$ rather than $\sqrt{\mathrm{MW}}$ will be the primary determinant of whether an individual inert gas fails to achieve intravascular equilibration. Thus, $\mathrm{SF}_{6}$, being the least soluble and second heaviest of the six MIGET gases, will correspondingly exhibit the lowest intravascular diffusivity, which, in the presence of an increased intravascular distance, may be sufficient to result in its failure to achieve equilibration within the blood phase and, hence, between blood and alveolar gas. Indeed, consistent with this proposed mechanism is the simple but pertinent observation that, when compared with more soluble inert gases, $\mathrm{SF}_{6}$ takes a substantially longer time to achieve complete pressure equilibration when exposed to a body of blood in a closed system [25]. There is also experimental evidence that, even in the normal lung, small but measurable diffusion limitation does occur for the respiratory elimination of some intravenously infused inert gases [26].

The ideal experimental approach to test for individual inert gas diffusion limitation requires inert gases with very similar $\lambda$ but widely varying $\sqrt{ }$ MW [26]. This is in fact opposite to what is provided by the MIGET analysis. Nevertheless, it has frequently been proposed that both in health and disease, diffusion-limitation of individual MIGET gases should be readily detectable by consideration of the respective retentions $(\mathrm{R})$ and blood:gas partition coefficents (i.e. $\lambda$ ) of all six gases [14, 21, 27]. The theoretical basis for such an approach is that, in a homogeneous gas-exchanging lung in which there is complete alveolo-capillary inert gas equilibration, the inverse of individual gas $\mathrm{R}$ and $\lambda$ values (and corresponding logarithmic transformations $\ln (1-\mathrm{R} / \mathrm{R})$ and $\mathrm{In} \lambda)$ are linearly related $[14,26]$. Thus, a gas which is diffusion-limited will diverge from the linear relationship determined by the other five diffusion-independent gases. However, such relationships become increasingly alinear with increasing degrees of simulated $V^{\prime} \mathrm{A} / Q^{\prime}$ inequality [26] and shunt (Crawford et al. unpublished observations) with the most poorly soluble gases diverging most (fig. 2a).

Since we are proposing that any diffusion-limitation is occurring within the blood phase, wherein the solubility of a given inert gas is the primary determinant of its ability to achieve intravascular equilibration, any relative diffusion-limitation would be most likely to occur (and hence most likely to be detectable) between the two least soluble MIGET inert gases, i.e. $\mathrm{SF}_{6}$ and ethane. Thus, if there is significant diffusion limitation for $\mathrm{SF}_{6}$, one would predict that its retention should be relatively greater than that of ethane. However, as already pointed out above, the greater the shunt the more $\mathrm{SF}_{6}$ will be retained relative to ethane, without the need to invoke diffusion-limitation specific for $\mathrm{SF}_{6}$ (fig. 2a). In the oxygen runs, we have two estimates of shunt: that determined by MIGET $\left(Q_{\mathrm{s}}^{\prime} / Q_{\mathrm{t}}^{\prime}=25 \%\right)$ and that by the classical oxygen method $\left(Q_{\mathrm{s}}^{\prime} / Q_{\mathrm{t}}^{\prime}=18 \%\right)$. The measured retention of $\mathrm{SF}_{6}$ relative to that of ethane $\left(\mathrm{SF}_{6} \mathrm{R} / \mathrm{EthR}\right)$ has, for the three $\mathrm{O}_{2}$ runs, a mean value of 0.77 (range $0.75-0.84$ ). In contrast, a simulation, utilizing a modified version of the lognor programme of WEST, and which assumes inert gas diffusion equilibration [22], predicts, for the same input variables $V^{\prime} \mathrm{A}, Q^{\prime}$, ventilation-perfusion inequality and shunt as quantified by the MIGET analysis an $\mathrm{SF}_{6} \mathrm{R} / \mathrm{EthR}$ of 


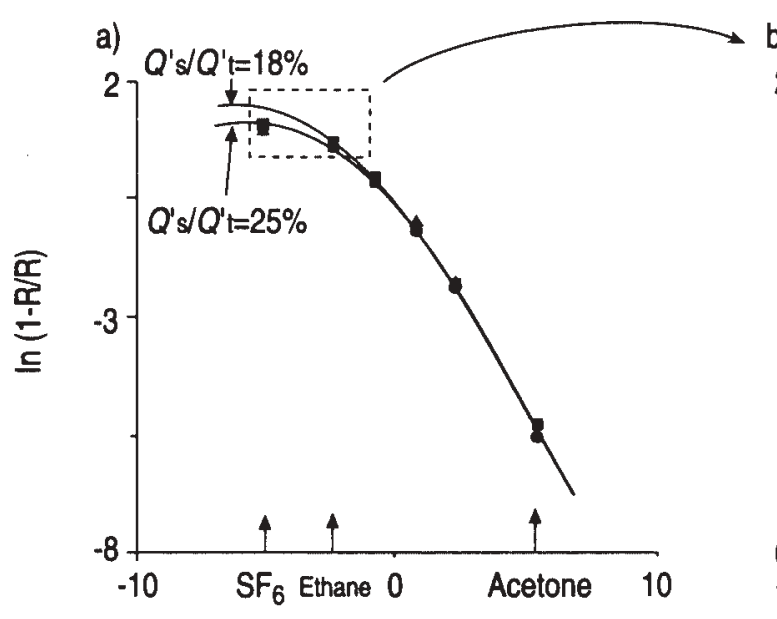

In blood:gas partition coefficient

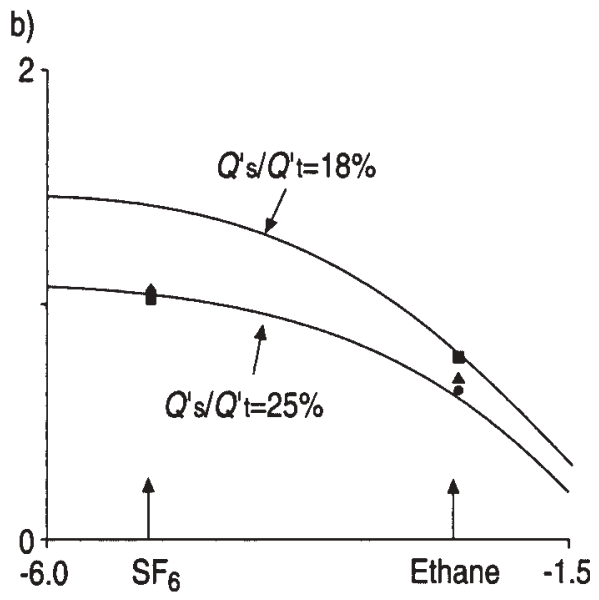

In blood:gas partition coefficient

Fig. 2. - a) Plots of the logarithmic inert gas blood: gas partition coefficients (i.e. solubilities, $\lambda$ ) versus corresponding logarithmic 1-R/R where $\mathrm{R}$ is the inert gas retention, for model simulations which assume inert gas diffusion equilibration and with simulated shunt values (Sim $Q^{\prime}$ 's $\left.Q^{\prime}\right)$ of 25 and $18 \%$ corresponding to those estimated from the MIGET analysis and oxygen method, respectively. The individual values from the three experimental runs $(\mathbf{0}, \mathbf{0}, \mathbf{\Delta})$ obtained during $100 \%$ oxygen breathing are superimposed. Note that in both cases, the respective values of the least soluble gases (hatched box) diverge most from linearity. b) Same axis and symbols as in (a), but limited to those values encompassed by the hatched box in (a). Note that the experimental values for $\mathrm{SF}_{6}$ are satisfactorily predicted by the simulation with a shunt of $25 \%$, but not by the simulation with an $18 \%$ shunt. However, neither simulation adequately predicts the experimental values for ethane. MIGET; multiple inert gas elimination technique; $Q_{\mathrm{s}}^{\prime} / Q_{\mathrm{t}}^{\prime}$ : pulmonary shunt fraction; $\mathrm{SF}_{6}$ : sulphur hexafluride.

0.69. The same simulation, but with a shunt value of $18 \%$ (corresponding to that estimated by the oxygen method), predicts an even smaller $\mathrm{SF}_{6} \mathrm{R} / \mathrm{EthR}$ of 0.64 . Thus, at least within the range of shunt values estimated experimentally, the measured retention of $\mathrm{SF}_{6}$ is relatively greater than that of ethane when compared with simulations that do not allow for possible inert gas diffusion-limitation (fig. 2b).

When the individual raw measured retentions for $\mathrm{SF}_{6}$ and ethane are compared with those predicted from the curve fitting procedure utilizing the retention values of

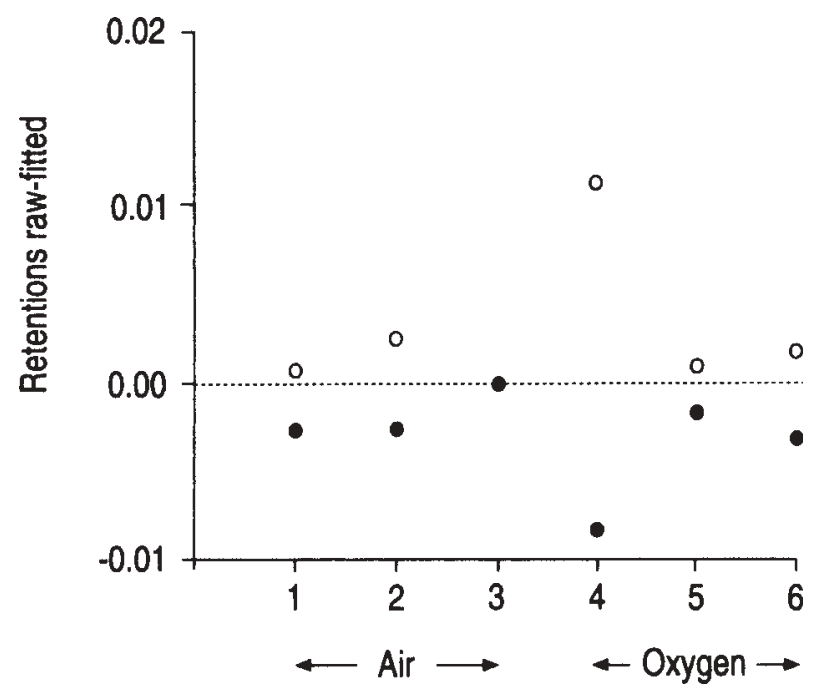

Fig. 3. - Individual measured retentions (raw) of $\mathrm{SF}_{6}$ and ethane minus their corresponding retentions predicted from the fitting procedure utilizing the measured retentions of all six MIGET inert gases (fitted) for the six experimental runs. Note that in five of the six runs there is a consistent and opposite dispersion away from zero for the two gases, the pattern of which would be consistent with diffusion-limitation specific for $\mathrm{SF}_{6}$ relative to ethane. $\mathrm{O}$ : SF6; ethane. For abbreviation see legend to figure 2 . all six inert gases, in five of the six experimental runs the retention of $\mathrm{SF}_{6}$ estimated from the curve fit is less than that actually measured, whereas the opposite is the case for ethane (fig. 3). This consistent dispersion of the two least soluble inert gases implies there is an additional factor determining the relative retention characteristics of these two gases which is not influencing the other more soluble gases. This is exactly what might be predicted in the event of a specific diffusion-limitation for $\mathrm{SF}_{6}$ relative to ethane.

In the context of the current study, diffusion-limitation for $\mathrm{SF}_{6}$ would have resulted in an increase in its retention relative to excretion, which the MIGET analysis, since it assumes inert gas equilibration, would have attributed to $V^{\prime} \mathrm{A} / Q^{\prime}$ inequality and/or shunt. Thus, the degree of $V^{\prime} \mathrm{A} / Q^{\prime}$ inequality and/or shunt would have been overestimated and that due to $\mathrm{O}_{2}$ diffusion limitation underestimated. Similarly, even the $\mathrm{O}_{2}$ method can only be regarded as a true quantification of intrapulmonary shunt if, in fact, $100 \% \mathrm{O}_{2}$ is sufficient to completely overcome any underlying $\mathrm{O}_{2}$ diffusion-limitation. However, even this assumption may be questioned in the presence of severe alveolo-capillary diffusion-limitation [28, 29].

Acknowledgements: The authors gratefully acknowledge the help of V. Antico in the performance and analysis of the whole body scintiscans and J. Walker for manuscript preparation.

\section{References}

1. Bertholet P, Walker JG, Sherlock S, Reid L. Arterial changes in the lungs in cirrhosis of the liver; lung spider naevi. N Engl J Med 1966; 274: 291-298.

2. Wolfe JD, Tashkin DP, Holly FE, Brachman MB, Genovesi MG. Hypoxemia of cirrhosis. Am J Med 1977; 63: 746-754 
3. Stanley NN, Williams AJ, Dewar CA, Blendis LM, Reid L. Hypoxia and hydrothoraces in a case of liver cirrhosis: correlation of physiological, radiographic, scintigraphic and pathological findings. Thorax 1977; 32: 457-471.

4. Genovesi MG, Tierney DF, Taplin GV, Eisenberg H. An intravenous radionuclide method to evaluate hypoxemia caused by abnorrnal alveolar vessels: limitation of conventional techniques. Am Rev Respir Dis 1976; 114: 59 65 .

5. Krowka MJ, Cortese DA. Hepatopulmonary syndrome; an evolving perspective in the era of liver transplantation. Hepatology 1990; 11: 138-142.

6. Davis HH, Schwartz DJ, Leftrak SS, Susman N, Schainker BA. Alveolar-capillary oxygen disequilibrium in hepatic cirrhosis. Chest 1978; 73(4): 507-511.

7. Krowka MJ, Cortese PA. Severe hypoxemia associated with liver disease: Mayo Clinic experience and the experimental use of almitrine bimesylate. Mayo Clin Proc 1987; 62: 164-173.

8. Shijo HS, Hisano SH, Sasaki H et al. Detection of pulmonary telangiectasia using dynamic pulmonary perfusion imaging in patients with liver cirrhosis. Clin Nuc Med 1989; 14: 179-182.

9. Mélot C, Naeije R, Deschamps SP, Hallemans R, Lejeune P. Pulmonary and extra-pulmonary contributors to hypoxemia in liver cirrhosis. Am Rev Respir Dis 1989; 139: 632-640.

10. Edell ES, Cortese DA, Krowka MJ, Rehder K. Severe hypoxemia and liver disease. Am Rev Respir Dis 1989; 140: 1631-1635.

11. Augusti AGN, Roca J, Bosch J, Rodriguez-Roisin R The lung in patients with cirrhosis. J Hepatology 1990; 10: 251-257.

12. Gates GF, Orme HW, Dore EK. Cardiac shunt assessment in children with macroaggregated albumin technetium-99m. Radiol 1974; 112: 649-653.

13. Chilvers ER, Peters AM, George P, Hughes JMB, Allison DJ. Quantification of right to left shunt through pulmonary arteriovenous malformation using ${ }^{99 \mathrm{~m}} \mathrm{Tc}$ albumin microspheres. Clin Radiol 1988; 39: 611-614.

14. Wagner PD, Laravuso RB, Uhl RB, West JB. Continuous distribution of ventilation-perfusion ratios in normal subjects breathing air and $100 \% \mathrm{O}_{2}$. J Clin Inv 1974; 54: 54-68.
15. Young IH, Corte P, Schoeffel RE. Pattern and time course of ventilation-perfusion inequality in exercise-induced asthma. Am Rev Respir Dis 1982; 125: 304-311.

16. Castaing Y, Manier G. Haemodynamic disturbances and V'A/Q' matching in hypoxemic cirrhotic patients. Chest 1989; 96: 1064-1069.

17. Nakamura T, Nakamura S, Tazawa S, et al. Measurement of blood flow through portopulmonary anastosmosis in portal hypertension. J Lab Clin Med 1965; 65: 114-121.

18. Nair PK, Hellums JD, Olson JS. Prediction of oxygen transport rates in blood flowing in large capillaries. Microvasc Res 1989; 38: 269-285.

19. Coin JT, Olson JS. Rate of oxygen uptake by human red blood cells. J Biol Chem 1978; 254: 1178-1190.

20. Vandergrif KD, Olson KD. Morphological and physiological factors affecting oxygen uptake and release by red blood cells. J Biol Chem 1984; 259: 1261912627.

21. Wagner PD, Dantzker DR, Dueck R, Clausen JI, West JB. Ventilation-perfusion inequality in chronic obstructive pulmonary disease. J Clin Invest 1977; 59: 203216.

22. West JB, Wagner PD. Pulmonary gas exchange. In: West JB, ed. Bioengineering aspects of the lung. New York, Marcel Dekker, 1977; pp. 361-364.

23. Corte P, Young IH. Ventilation-perfusion relationships in symptomatic asthma. Response to oxygen and clemastine. Chest 1985; 88: 167.

24. Wagner PD. Diffusion and chemical reaction in pulmonary gas exchange. Physiol Rev 1977; 57: 257-312.

25. Wagner PD, Naumann PF, Laravuso RB. Simultaneous measurement of eight foreign gases in blood by gas chromatography. J Appl Physiol 1974; 36: 600-605.

26. Robertson HT, Whitehead J, Hlastala MP. Diffusion-related differences in elimination of inert gases from the lung. J Appl Physiol 1986; 61: 1162-1172.

27. Wagner PD, West JB. Ventilation-perfusion relationships In: West JB, ed. Pulmonary Gas Exchange. Academic Press, Vol. 1, 1980; pp. 242-243.

28. Mazal D, Briscoe WA, King T. The effect of severe uneven impairment of diffusing capacity on the arterial oxygen profile: a theoretical study. Am Rev Respir Dis 1980; 121: 378 (Suppl.)

29. Thorens JB, Junod AF. Hypoxaemia and liver cirrhosis: a new argument in favour of a "diffusion-perfusion defect". Eur Respir J 1992; 5: 754-756. 